\title{
Approaches to Changing Behaviours: Designing an Intervention to Reduce Sedentary Behaviour in the Workplace using Behaviour Change Theory
}

\author{
Matt Coldrey* \\ HE Sport, University Centre Hartpury, UK
}

Submission: May 21, 2018; Published: May 29, 2018

*Corresponding author: Matt Coldrey, Lecturer, HE Sport, University Centre Hartpury, Gloucester, UK, Tel: +44 1452 702481; Email: Matt.Coldrey@Hartpury.ac.uk

\begin{abstract}
The aim of this article is to present a specific example of the application of the use of behaviour change theory to design workplace physical activity interventions, and to provide a conceptual guide for workplaces to follow. As a part of a wider National Health Service Clinical Commissioning Group initiative to improve the overall health and wellbeing of the county's workforce, a County Sports Partnership were commissioned to design and implement an intervention to increase the physical activity levels of employees within the workplace.

The intervention was designed using a behaviour change approach, drawing upon the COM-B (Capability, Opportunity and Motivation equals' behaviour) model. Workplace needs were analysed, focusing on the three areas of business need, workplace environment and employee need. These needs were then analysed, and using a policy approach, workplaces designed long-term action plans to shift the sedentary behaviours identified via the needs analysis, through a range of bespoke measures.
\end{abstract}

Keywords: Physical Activity; Workplace; Behaviour Change; Health, Productivity; Business, Employee; Employer

\section{Introduction}

The workplace is an ideal setting for the promotion of physical activity, with the potential to develop the mutually beneficial aim of raising employees' physical activity levels. The link between individuals' physical activity levels and health and wellbeing are well documented [1]. Physical activity is linked to improved physical health with the reduced risk of chronic disease (e.g. cardiovascular disease, diabetes, cancer, hypertension, obesity, depression and osteoporosis), increased physical fitness and strength, and increased energy levels [2]. In fact, any breaks from sedentary time are beneficial to weight control and reducing obesity [3]. Furthermore, physical activity is also linked with improved mental health with the reduction of stress, serotonin release that alleviates depression and anxiety symptoms, as well as improving mood and self-esteem [4]. Physical activity sessions lead to feelings of lowered tension and exhilaration meaning that exercise could be an effective shortterm strategy for self-regulation of mood.

Overall, ill health is estimated by the UK government to cost over the UK economy $£ 100$ billion each year, and equates to 172 million sick days. That translates to a combined cost of $£ 13$ billion to employers. In addition to the costs of absenteeism, 6 million workers claim to have a long-standing health condition, leading to a rise in the presenteeism and leavism, which Professor Cray Cooper argues costs twice that of absenteeism [5]. Therefore, by actively encouraging and supporting employees to increase their physical activity levels, employers stand to benefit by combating the additional costs that unhealthy employees present. With increased physical activity levels leading to a reduction in both physical and mental health issues, it is in employers' interests to actively promote and investing in their employees' physical activity levels. In fact, when an employer is seen to be actively looking out for its employee's health and wellbeing, it has better retention rates than those who do not [6]. Staff turnover is another expense to businesses, with the costs of recruitment and training, and with it taking up to 32 weeks for new employees to reach peak performance [7].

In addition to the health benefits of increased physical activity levels, it also affects creative thought, improved memory and increased cognitive performance [8]. Physical activity also has a positive influence on coping skills, and tolerating minor irritations. The benefits of increased physical activity on both employee and employer build a picture that communicates the importance of employers actively encouraging and championing increasing physical activity levels within its employees. 
Furthermore, a comparative study between days when employees exercised and no-exercise days showed that employees reported increased workplace performance however, the same employees reported that they sometimes found it difficult to organise their working days to include physical activity.

The traditional models of production, for example, the Six Sigma and Toyota Production System, operate under the Kaizen philosophic assumption that increased hours working lead to increased productivity, despite there being no empirical evidence supporting this notion [9-11]. However, research does suggest that taking regular breaks, especially when they include physical activity, increases productivity by increasing the pace of work during shorter periods by increasing focus, assisting with the formulation of ideas and retention of information, and helping with the revaluation of goals $[12,13]$. Therefore, the integration of breaks and physical activity into the working day is also an important consideration for employers.

\section{Intervention Design: Applying the Behaviour Change Wheel to Workplace Physical Activity}

The intervention was designed using a behaviour change approach, drawing upon the COM-B (Capability, Opportunity and Motivation equals' behaviour) model and Behaviour Change
Wheel (BCW). Workplace needs were analysed, focusing on the three areas of business need, workplace environment and employee need. These needs were then analysed, and using a policy approach, workplaces designed long-term action plans to shift the sedentary behaviours identified via the needs analysis, through a range of bespoke measures.

The COM-B model is a behavioural analysis and diagnosis tool, designed to understand the behaviours of individuals, within the context in which the behaviours take place [14]. Once understood, interventions can be designed using the behaviour change wheel, a synthesis of nineteen frameworks to organise interventions [15]. The Behaviour Change Wheel places the COM-B model within the centre, with nine intervention functions placed within the inner ring, and seven policy categories on the outer ring. Therefore, when designing a specific model for using within workplaces, it is important to consider what workplaces can control. The policy considerations are dealt with external agencies, and therefore, for specific workplace intervention design, these categories only play a contextual role. As a result, this piece will focus upon designing a model for increasing employee physical activity levels with the use of the COM-B model and nine intervention functions [16].

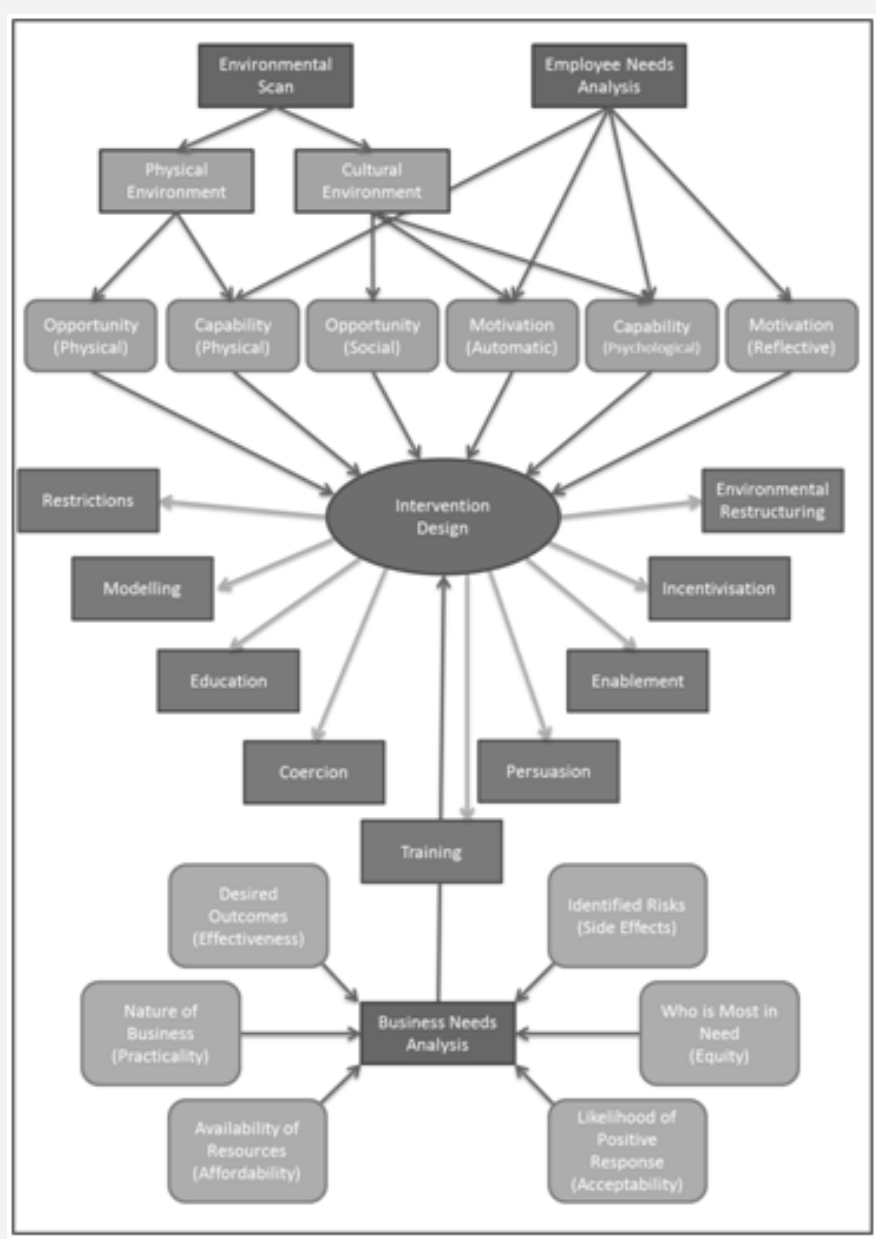

Figure 1: Workplace Physical Activity Intervention Model. 
Workplace needs were assessed, focusing on the three areas of business need, workplace environment and employee need. These needs were then analysed, and using a policy approach, workplaces designed long-term action plans to shift the sedentary behaviours identified via the needs analysis, through a range of bespoke measures. The approach targeted the employees' capability, opportunity and motivation, this approach sought to offer a holistic approach to shifting behaviours. Capability was targeted through the education of employees, showing them that they could increase their physical activity levels at work by doing simple and achievable activities that were both modelled. Activities were also drawn from the participants themselves during the training. By providing staff with simple and achievable activities to do and by providing them with the option stand up whilst they worked by installing sit-down/stand-up desks, staff were given the opportunity to increase their physical activity levels, whilst not taking up their valuable time. The employees' motivation was targeted by educating them on the impact on their work performance, physical health, and mental wellbeing $[17,18]$ (Figure 1).

The nine intervention functions that make up the overall intervention design offer a holistic approach to shifting behaviours of employees. The use of these nine intervention functions should be informed by the capabilities, motivations of, and opportunities available to, the target population. Also being considered is the context of the workplace itself, and the overall aims of the intervention. The BCW framework takes into account the context of the intervention naturally through these three influencing factors upon the behaviour of individuals. Therefore, it is essential that the intervention design is fully informed by these three factors. It is proposed that a business needs analysis, physical and environmental scan, and an employee needs analysis is undertaken to inform the design of the intervention. Then, it is proposed that each of the nine intervention functions are considered in relation to the findings of these scans and analysis. Examples of each of the nine intervention functions are detailed below.

\section{Restrictions}

Look to place restrictions on how sedentary employees are allowed to be. Take care not to restrict employees against their wishes as this can lead to disengagement, demotivation and/or resentment.

\section{Example actions:}

a) Moving essential facilities, such as toilets and kitchens, further away from working areas.

b) Create a rule that means the lifts can only be used when necessary (i.e. if an employee is injured or disabled, or has to transport heavy or cumbersome items).

c) Place a limit onsite parking to those who need to use spaces close to the worksite. d) Place a limit the length of meetings with no breaks.

e) Place a limit on the amount of time employees are allowed to sit down continuously.

\section{Modelling}

Give positive role models exposure to encourage employees to emulate positive behaviours. Ensure that these role models are relatable and realistic for a range of employees (i.e. a super keen marathon runner will not interest individuals who have not been for a run in years).

Example actions:

a) Encourage staff to blog about their physical activity journey, or share blogs from individuals who are relatable to employees.

b) Place a sitting agenda item on team meetings for staff to share what physical activity they are been doing. Enable staff to ask questions and discuss this (be careful to get a mixture of already actives, sporadically active and inactive employees).

c) Create a bring-a-buddy scheme, where employees share what physical activity they are doing, and invite their colleagues along to try. This can be done as a team-building activity, but ensure that you do not force employees to take part in activities they do not want to.

d) Invite inspirational speakers to talk to staff about their journey from inactive, to physically active.

\section{Education}

Enable employees to learn about physical activity and the way in which it can positively impact upon their physical and mental wellbeing. Example actions:

a) Offer staff development/education that looks at educating staff on the benefits of being physically active on the health and wellbeing, as well as their work performance and productivity, and looks at how they can increase their physical activity levels.

b) Provide digital resources that inform employees via email, intranet sites and social media.

c) Display posters around the worksite at key areas such as by the kettle, next to lift doors, and on the back of toilet doors that encourage employees to make informed decisions about their own health and wellbeing.

d) Talk about the benefits of physical activity during team meetings, and ask employees to talk research and talk about the benefits.

e) Display screen savers that remind and educate employees on the benefits of physical activity, and how they can integrate it into their day. 


\section{Coercion}

Using punishments to control the behaviours of employees, but be careful to ensure that coercion is only used if employees have suggested a need and want to be coerced into shifting their behaviours. Top-down coercion can lead to disengagement, demotivation and resentment. Example actions:

a) Punish employees if meetings overrun by not allowing them to book the meeting room again for a week.

b) Punish employees who sit for over an hour without moving by not allowing them to use the staff car park for a day.

c) Ban employees from using toilets that are on the same floor as their workstation.

\section{Training}

Help employees to develop the key competencies that they need to be physically active. Example actions:

a) Offer cycle proficiency training.

b) Provide training on suitable office based activities and stretches.

c) Use motivational interviewing to motivate employees to become more physically active as a part of your appraisal scheme.

\section{Persuasion}

Regularly communicate with staff about the positive impact that physical activity can have, and the negative impact that sedentary behaviour can have. Example actions:

a) Remind employees of the need to be physically active throughout the day if you notice sedentary behaviour.

b) Integrate physical activity advice into your return-towork process.

c) Identify issues that employees face that physical activity can help to target (i.e. productivity, mental wellbeing, drowsiness, high levels of minor and mental illness) and target these by reminding employees that physical activity can help to address these issues.

\section{Enablement}

Make it easy for employees to make positive decisions about their physical activity levels. Ensure that staff know that you encourage them to increase their physical activity levels. Example actions:

a) Offer flexible working to allow employees to exercise before, and after work, and during lunch breaks.

b) Offer a reduced or free gym membership for employees.

c) Communicate local walking and cycling routes to staff to help them to find routes to actively travel to work.

\section{Incentivisation}

Create a reward scheme for employees who are already active, or who increase their physical activity levels. Example actions:

a) Provide employees with a fitness tracker at a reduced price based on the amount of steps they take (i.e. the more steps they take, the cheaper the payment for the month is).

b) Offer employees cycle/walk-to-work mileage to encourage them to cycle/walk all or part of their journey to and from work.

c) Offer employees business mileage for when the ride or walk to meetings.

\section{Environmental Restructuring}

Create a physical environment that enables employees to be physically active, and removes the physical barrier to being physically active.

Example actions:

a) Build and onsite gym, or provide a space for employees to be physically active.

b) Map out local walking routes, and create a local mile that staff can walk before and/or after work, or during lunch breaks.

c) Ensure staff have access to stairs.

d) Provide showering facilities onsite for staff who cycle or run to work, or who want to be active during their lunch breaks.

e) Provide secure cycle parking.

f) Provide employees with a table tennis table, or pop up table tennis set for during breaks.

\section{Conclusion}

This article sets out a blueprint for the design of workplace physical activity interventions with the long term aims of shifting employee behaviours with regard to physical activity. Within the UK, there is an evident need for increasing the physical activity levels of individuals within the work place for the benefit of, not only individual workplaces, but also for the wider economy and health of the nation. A range of environmental, personal, and contextual factors influence the physical activity levels of employees, and by understanding and targeting specific areas, it is proposed that this blueprint will enable workplaces to design and implement effective interventions that will lead to positive health and productivity outcomes. However, this is just a blueprint based upon conceptual knowledge, and empirical research will be required to ascertain the effectiveness of the proposed framework.

\section{References}

1. O'Donovan G, Blazevich AJ, Boreham C, Cooper AR, Crank H, et al. (2010) The ABC of Physical Activity for Health: a consensus statement 
from the British Association of Sport and Exercise Sciences. Journal of sports sciences 28(6): 573-591.

2. Teixeira PJ, Carraça EV, Markland D, Silva MN, Ryan RM (2012) Exercise, physical activity, and self-determination theory: A systematic review. International Journal of Behavioral Nutrition and Physical Activity 9(1): 78.

3. Swartz AM, SquiresL, Strath SJ (2011) Energy expenditure of interruptions to sedentary behavior. International Journal of Behavioral Nutrition and Physical Activity 8(1): 69.

4. Bouchard C, Blair SN, Haskell W (2012) Physical activity and health. Human Kinetics.

5. Lu L, Lin HY, Cooper CL (2013) Unhealthy and present: Motives and consequences of the act of presenteeism among Taiwanese employees. Journal of occupational health psychology 18(4): 406-416.

6. Wright TA, Huang CC (2012) The many benefits of employee well-being in organizational research. Journal of Organizational Behavior 33(8): 1188-1192.

7. Oxford Economics (2014) The cost of brain drain: Understanding the financial impact of staff turnover.

8. Oppezzo M, Schwartz DL (2014) Give your ideas some legs: The positive effect of walking on creative thinking. Journal of experimental psychology: Learning, memory, and cognition 40(4): 1142

9. Sugimori Y, Kusunoki K, Cho F, Uchikawa S (1977) Toyota production system and kanban system materialization of just-in-time and respectfor-human system. The International Journal of Production Research 15(6): 553-564.
10. Pyzdek T, Keller PA (2014) The six sigma handbook. McGraw-Hil Education p. 25

11. Ariga A, Lleras A (2011) Brief and rare mental "breaks" keep you focused: Deactivation and reactivation of task goals preempt vigilance decrements. Cognition 118(3): 439-443.

12. Christoff K, Gordon AM, Smallwood J, Smith R, Schooler JW (2009) Experience sampling during fMRI reveals default network and executive system contributions to mind wandering. Proceedings of the National Academy of Sciences 106(21): 8719-8724.

13. Oakley BA (2014) A mind for numbers: How to excel at math and science (even if you flunked algebra). JP Tarcher.

14. Michie S, Van Stralen MM, West R (2011) The behaviour change wheel: a new method for characterising and designing behaviour change interventions. Implementation science 6(1): 42.

15. Michie S, Atkins L, West R (2014) The behaviour change wheel: a guide to designing interventions. Needed: Physician leaders 26: 146.

16. Ogden J (2016) Celebrating variability and a call to limit systematisation: The example of the Behaviour Change Technique Taxonomy and the Behaviour Change Wheel. Health psychology review 10(3): 245-250.

17. Michie S, Johnston M (2012) Theories and techniques of behaviour change: Developing a cumulative science of behaviour change, Health Psychology Review 6(1): 1-6.

18. Warburton DE, Nicol CW, Bredin SS (2006) Health benefits of physical activity: The evidence. Canadian medical association journal 174(6): 801-809.

\section{Your next submission with Juniper Publishers} will reach you the below assets

- Quality Editorial service

- Swift Peer Review

- Reprints availability

- E-prints Service

- Manuscript Podcast for convenient understanding

- Global attainment for your research

- Manuscript accessibility in different formats

( Pdf, E-pub, Full Text, Audio)

- Unceasing customer service

Track the below URL for one-step submission https://juniperpublishers.com/online-submission.php 